$15^{\text {th }}$ International Conference on

AEROSPACE SCIENCES \& AVIATION TECHNOLOGY,

ASAT - 15 - May 28 - 30, 2013, Email: asat@mtc.edu.eg,

Military Technical College, Kobry Elkobbah, Cairo, Egypt,

Tel: +(202) 24025292 -24036138, Fax: +(202) 22621908

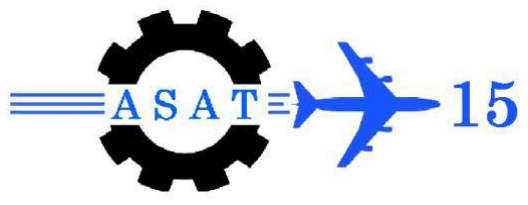

\title{
Effect of Pressure Gradient on Film Cooling From Holes Supplemented by Anti-Vortex Holes
}

\author{
M. A. H. Abdel-Mohimen ${ }^{*}$, T. A. Meakhail ${ }^{\dagger}$, S. S. Ayad ${ }^{\ddagger}$, K. El-Shazly ${ }^{\ddagger}$
}

\begin{abstract}
An experimental test rig is constructed to study the effect of pressure gradient on different configurations of the anti-vortex film cooling technique. This technique depends on adding a pair of cylindrical anti-vortex holes branching out from the main cylindrical film cooling holes to mitigate the effect of kidney vortices that causes the jet to lift off. Four different values of velocity ratios (VR), (Coolant Jet Velocity/Main Stream Velocity) namely $\mathrm{VR}=0.5,1.0,1.5$, and 2.0, are studied with three different positions of anti-vortex holes. A single row of $30^{\circ}$ angled holes on a flat surface, under zero pressure gradient along the downstream test surface, is taken as a baseline case. The numerical study is carried out using FLUENT commercial code using the $k-\varepsilon$ model. The density ratio is taken in consideration. Numerical results are first compared with experimental values of temperatures and film cooling effectiveness and the comparisons verified the numerical model. Both of experimental and numerical studies show that the new technique improves the film cooling effectiveness. The numerical velocity vectors in the boundary layer region showed that the anti-vortex holes create reverse vortices against the main vortices that are created by the main hole. These reverse vortices help in keeping the coolant jet flow near the surface. The adverse pressure gradient decreases the film cooling effectiveness while the presence of favorable pressure gradient increases the film cooling effectiveness.
\end{abstract}

Keywords: Film cooling, anti-vortex, turbine blade cooling.

\section{Nomenclature}

$B R \quad$ Blowing Ratio $=\left(\rho_{\mathrm{c}} \mathrm{U}_{\mathrm{c}} / \rho_{\mathrm{m}} \mathrm{U}_{\mathrm{m}}\right)$

$C p \quad$ Pressure coefficient $2\left(\mathrm{P}_{\mathrm{T}}-\mathrm{P}\right) / \rho \mathrm{Ue}^{2}$

$D \quad$ Film cooling main hole diameter

D Film cooling anti-vortex hole diameter

$H \quad$ Film cooling effectiveness

Ls Suction side length of the airfoil

$M R \quad$ Momentum Ratio $=\left(\rho_{\mathrm{c}} \mathrm{U}_{\mathrm{c}}^{2} / \rho_{\mathrm{m}} \mathrm{U}_{\mathrm{m}}{ }^{2}\right)$

$\mathrm{N} \quad$ Kinematic viscosity of the fluid

$\mathrm{P}_{\mathrm{T}} \quad$ Upstream stagnation pressure

$R e_{D} \quad$ Injectant Reynolds number $=\mathrm{Uc} * \mathrm{D} / v_{\mathrm{c}}$
$R e_{x} \quad$ Free stream Reynolds number $=\mathrm{U}_{\mathrm{m}} * \mathrm{x} / \mathrm{v}_{\mathrm{m}}$

$T_{a w} \quad$ Adiabatic wall temperature

$T_{c} \quad$ Coolant air temperature

$T_{f} \quad$ Local film temperature

$T_{m} \quad$ Mainstream air temperature

$U_{c} \quad$ Coolant air velocity

$U_{m} \quad$ Mainstream air velocity

$V R \quad$ Velocity Ratio $=\mathrm{U}_{\mathrm{c}} / \mathrm{U}_{\mathrm{m}}$

$X \quad$ Distance from the film hole centerline

Lecturer, Mech. Eng. Dept., Shoubra Faculty of Engineering, Benha University, Egypt, melmohimen2@yahoo.com.

$\dagger \quad$ Assocaite Prof. Faculty of Energy Engineering, Aswan University, Egypt, mina_tarek@hotmail.com .

Professor, Mech. Eng. Dept., Shoubra Faculty of Engineering, Benha University, Egypt. 


\section{Greek Symbols}

$\rho \quad$ Density of the fluid

$\bar{\eta} \quad$ Average film cooling effectiveness

$\overline{\bar{\eta}} \quad$ Overall film cooling effectiveness
Subscripts

C $\quad C$

$M \quad M$

\author{
Abbreviations \\ APG \\ Adverse Pressure Gradient \\ APG(1) \\ The first adverse pressure gradient \\ APG(2) \\ The second adverse pressure gradient \\ APG \\ Adverse Pressure Gradient \\ FPG \\ The favorable pressure gradient
}

\title{
Introduction
}

Film Cooling is the introduction of a secondary fluid (coolant or injected fluid) at one or more discrete locations along a surface exposed to a high temperature environment to protect that surface not only in the immediate region of injection but also in the downstream region [5]. Film cooling protects the surface directly by forming a protective layer of cold air as compared to internal cooling, where blade is cooled by extracting heat by convection. Film Cooling also provides cooling from internal convection in the film holes. Flat surface film cooling has been known and subjected to research for a long time. Goldstein et al. [6] described the effectiveness characteristics with lateral injection. The effectiveness following single hole of the inclination angle of 15 and $35 \mathrm{deg}$ are investigated. They reported that the effect of lateral injection is to widen the temperature field and decrease the peak effectiveness for the blowing ratio of $\mathrm{BR}=0.5$. For the higher blowing ratios, however, the lateral injection increases both the width of the temperature field and the peak film cooling effectiveness. Ammari et al. [1] also presented the effect of density ratio on heat transfer coefficient contours downstream of a film hole inclined $35^{\circ}$ along the stream-wise direction for two different coolant-to-mainstream density ratios of 1.0 and 1.52 for a coolant blowing ratio of $\mathrm{BR}=1.46$. Differences of $10 \%$ in film cooling occurred when coolant densities were changed.

Andreopoulous and Rodi [2] studied the behavior of a single jet and mainstream interaction. There is a mutual deflection of the jet and the mainstream. At a low momentum ratio $\mathrm{MR}=$ 0.25 , the mainstream pushes the jet to adhere to the bottom wall .At a higher momentum ratio $\mathrm{MR}=4.0$, the jet penetrates into the mainstream before it is bent. There have been vast studies in the field of interaction between coolant jet from inclined cylindrical holes and the mainstream flow. The interaction results in the formation of kidney vortices, i.e. a pair of counter rotating vortices as described by Haven et al. [7]. These vortices are detrimental to film cooling because it brings about two undesirable effects. Firstly, the hot mainstream air is forced to enter beneath the jet, thus heating the turbine blade wall. Secondly, the mutual interaction between the vortex pair tends to lift the jet off the turbine blade surface which diminishes the film cooling. Lemmon et al. [13] who showed that this vorticity is caused by the bending of the jet by the free-stream and not by viscous wall effects in the hole or plenum. For cases with varying density ratio, the momentum ratio is considered to be an even better predictor of jet lift-off than blowing ratio (BR) since higher density ratio jets will tend to remain attached to the surface at higher blowing ratios. Numerical prediction of flat surface film cooling also has been studied.

Alok Dhungel [3] investigated the enhanced cooling performance caused by addition of antivortex holes to the main cylindrical film cooling holes. Both heat transfer coefficient and film cooling effectiveness are determined experimentally downstream of the exit of the film 
cooling holes on a flat plate by a single test using the transient Infra Red thermography technique. A total of six different cases with variations in geometry and orientation of the anti vortex holes in relation to the main film cooling holes are thoroughly investigated. Results suggested that the presence of anti vortex holes mitigates the effect of the pair of anti vortices. Heidmann [8] and Heidmann and Ekkad [9] used a 3-D Navier-Stokes solver Glenn-HT which has been conceived and developed at NASA Glenn Research Center to study the "antivortex" film-cooling concept which is designed to mitigate the effects of the counter-rotating vortex pair, which reduces the effectiveness of circular cross-section film-cooling holes at moderate to high blowing ratios. Preliminary and improved designs concepts are developed in this study, although many parameters can be modified in an optimized design. The concept is applied in this study as a modification to a standard single row round film-cooling hole arrangement with the holes angled at 30 deg to the surface and a span-wise pitch of three hole diameters and is compared to the base line data of Dhungel et al [4].

Jubran and Brown [10] reported the effect of favorable pressure gradients on film cooling from simple angle injection holes. It was concluded that a moderately favorable pressure gradient tends to reduce the value of the average film cooling effectiveness downstream of the injection holes. Teekaram et al. [17] studied film cooling experimentally in the presence of a mainstream pressure gradient on a flat plate downstream of an inclined slot and a single row of holes in the presence of favorable and adverse pressure gradients. They found that an accelerating flow tends to increase the film cooling effectiveness over that for zero or adverse pressure gradient.

In the present work, the anti vortex technique is studied experimentally and numerically. The experimental and numerical studies will carried out under Zero Pressure Gradient (ZPG) and adverse pressure gradient (APG(1)) which is used to simulate the pressure gradient on the suction side of the "Pak-B" airfoil, which is an industry supplied research airfoil that is representative of a modern, aggressive Low Pressure Turbine (LPT) design. Another adverse pressure gradient (APG (2)) and favorable pressure gradient (FPG) are studied numerically to investigate the effect of different pressure gradients.

\section{Experimental Apparatus and Procedure}

A schematic of the wind tunnel and the injectant supply system is shown in Figure (1). The wind tunnel is an open-circuit and subsonic one, with 4 to 1 contraction ratio nozzle. The nozzle leads to the test section which is a square duct $(0.2 \mathrm{~m} \times 0.2 \mathrm{~m})$ with $2 \mathrm{~m}$ length. A boundary layer trip wire of $2 \mathrm{~mm}$ diameter is located on the test plate just downstream of the nozzle exit [11].

The film cooling jets supply unit consists of the air blower and the air control unit. The air blower forces air, to the test section through the air control unit. The air control unit consists of bypass and control valves to control the flow rate of air through the test section.

Experiments are conducted at the fixed free-stream mean velocity of $8.6 \mathrm{~m} / \mathrm{s}$ measured by a standard pitot tube. The Reynolds number $\left(\operatorname{Re}_{\mathrm{X}}\right)$ based on the distance between the trip wire and the hole center is 452,744 . The velocity ratio (VR) is the ratio of the injectant mean velocity to free-stream mean velocity. The velocity ratio values are $0.5,1.0,1.5$, and 2.0. The corresponding injectant Reynolds numbers $\left(\mathrm{Re}_{\mathrm{D}}\right)$ are 2929, 5347, 7562, and 10695, respectively. The injectant is heated to a temperature twice the free stream temperature. The density ratio of injectant to free-stream due to the heating is 0.94 . Thus, the momentum ratio values are $0.313,1.044,2.09$ and 4.18 for velocity ratios of $0.5,1.0,1.5$, and 2.0 , respectively. 
In Anti-vortex cases, the injectant velocity is calculated at the inlet of the holes to have the same velocity ratios.

A row of five holes is located $80 \mathrm{D}$ downstream of the trip wire. The hole spacing between the hole centers is $3 \mathrm{D}$. The bottom plate of the duct consists of an upstream plate, a film-hole plate, and a test plate. The test plate starts at $\mathrm{x} / \mathrm{D}=1.5$. To prevent the adiabatic wall temperature elevation near the downstream edge of the holes, the injection holes are machined in the injection plate, not in the measurement plate.

To measure the temperature distribution on the test surface, the test surface has 13 rows of 7 holes drilled for 91 calibrated K-type thermocouples. The hole diameters are $1 \mathrm{~mm}$ and the distance from one to another is $5 \mathrm{~mm}$. Thermocouples are inserted from the bottom of the Plexiglas so that the welded bead of the thermocouple is flush with the top surface. The thermocouples are glued into place with a two part Epoxy adhesive. The test surface and thermocouple beads are then covered with a thin foil to ensure a smooth continuous test surface. The thermocouples are centered at the front of the air jets of the middle hole.

Baseline case is a flat plate with five inclined holes. The diameter of each hole is $10 \mathrm{~mm}$ and the spacing between the holes is 3D. The length of holes is 4D. The holes are inclined to the horizontal at an angle of $30^{\circ}$ along the flow direction. A pair of anti-vortex holes are added each to all the five film cooling holes. The orientations and other geometries of the primary film cooling hole is the same as the baseline, only the features of the anti vortex film cooling holes are altered.

Three different geometries are investigated:

As shown in figure (2) (a), The distance between the center of the anti vortex holes and the center of the primary film cooling holes measured in the x-direction is represented by parameter ' $\mathbf{a}$ '. The similar distance measured in the $\mathbf{y}$ - direction is given by parameter ' $\mathbf{b}$ '. The angles measured in degrees between the axis of the primary film cooling holes and the anti vortex holes measured in the front vertical plane and the side vertical planes are represented by parameters ' $\mathbf{R}$ ' and parameter ' $Q$ ' respectively. Table (1) shows the values of D, d, a, b, R, Q for studied cases.

Case-1: as shown in figure (2) (b), the anti vortex holes shoot out vertically upwards from the primary film cooling holes and thus the exit of the anti vortex holes is far upstream as compared to the exit of the primary film cooling hole. The anti vortex hole originate from the lower end of the primary film cooling hole

Case-2: as shown in figure (2) (c), the exit of the anti vortex film cooling holes are still upstream to the outlet of the primary film cooling hole but isn't far as compared to case- 1 . Both the anti vortex film cooling holes are symmetrical in orientation and location to the primary film cooling hole.

Case-3: as shown in figure (2) (d), the exit of the anti vortex film cooling hole geometry is in line with the primary film cooling holes. The anti vortex holes branch out near the middle point of the primary film cooling holes. 
Table 1: Test Plate details (depending on Fig. 2 (a)) (Dimensions in $\mathrm{mm}$ and angles in degrees)

\begin{tabular}{c|c|c|c}
\hline \hline & Case 1 & Case 2 & Case 3 \\
\hline $\mathrm{D}$ & 10 & 10 & 10 \\
\hline $\mathrm{d}$ & 5 & 5 & 5 \\
\hline $\mathrm{a}$ & 10 & 10 & 10 \\
\hline $\mathrm{B}$ & 30 & 15 & 0 \\
\hline $\mathrm{Q}$ & 90 & 49.1 & 30 \\
\hline $\mathrm{R}$ & 30 & 30 & 30 \\
\hline \hline
\end{tabular}

To create a streamwise pressure gradient without modifying the wall curvature, a wedge was inserted into the wall opposite to the flat plate. The wedge profile was constructed to give a pressure distribution close to that over the suction side of "Pak-B" airfoil, figure (3), which is an industry supplied research airfoil that is representative of a modern, aggressive Low Pressure Turbine (LPT) design [16]. Figure (4 (d)) shows the pressure coefficient profiles over the flat plate test section with studied wedges as compared with Pak-B Airfoil.

The place at which the coolant jet is injected has an adverse pressure gradient. Two adverse pressure gradients are studied numerically to be insuring of the effect of adverse pressure gradient. One favorable pressure gradient, is studied numerically to show the effect of favorable pressure gradient as compared with the adverse pressure gradient because both of adverse and favorable pressure gradients are already exist on the turbine blade surfaces. The wedge and its position with respect to the area of data collection for the first adverse (APG(1)), the second adverse (APG(2)), and the favorable (FPG) pressure gradients are shown in Figure (4 (a)), (4(b)), and (4(c)) respectively.

\section{Numerical Method}

Supporting the three-dimensional steady flow CFD studies are performed to gain a deeper insight into the flow field that is responsible for the observed coolant jet interaction with the mainstream. FLUENT is used to simulate film cooling for all anti-vortex geometries and compared to baseline case cylindrical holes. The computational grid is shown in Figure (5). The Figure highlights the grid quality near the hole intersection region for case (1). Symmetry boundary conditions were applied on all cases. This was done since the present study performed with a steady CFD analysis in which no flow can cross these planes because of symmetry. The boundary enditions are slightly different from the experiment and are prescribed at all three boundary surfaces of the computation domain. Mainstream conditions were maintained the same in all cases and the coolant flow rate was altered to change the velocity ratios. At solid walls, adiabatic boundary conditions are used, and no-slip boundary condition is set as: $\mathrm{U}_{\mathrm{W}}=0, \mathrm{~V}_{\mathrm{W}}=0, \mathrm{~W}_{\mathrm{W}}=0, \mathrm{u}_{\mathrm{i}} \mathrm{u}_{\mathrm{j}}=0$ where index $\mathrm{w}$ denotes the wall.

For the mainstream and the coolant jet velocity inlet, uniform profile is set. In our study, all the computations are performed with uniform flow inlet for the mainstream and the coolant jet. Standard total temperature value and inlet velocity were used at the mainstream inlet with flow normal to the inlet plane. The mainstream inlet is $20 \mathrm{D}$ upstream of the main hole center line. The plenum inlet mass flow rate was adjusted to produce the blowing ratio desired. The plenum inlet total temperature was set to 2 times the mainstream inlet total temperature. The effect of density difference was taken in consideration and the density ratio is about of 0.94 . A turbulence intensity of 1 percent and a turbulence length scale of $1 \mathrm{D}$ were specified at both the mainstream inlet and plenum inlet. 
The $\mathrm{k}-\varepsilon$ model is used to solve the governing equations. In FLUENT, there are three Models for k- $\varepsilon$ Solution (Standard, RNG, and Realizable k- $\varepsilon$ Models). The realizable k- $\varepsilon$ model is a relatively recent development and differs from the standard $\mathrm{k}-\varepsilon$ model in two important ways:

- The realizable k- $\varepsilon$ model contains a new formulation for the turbulent viscosity.

- A new transport equation for the dissipation rate has been derived from an exact equation for the transport of the mean-square vorticity fluctuation.

An immediate benefit of the realizable $\mathrm{k}-\varepsilon$ model is that it more accurately predicts the spreading rate of both planar and round jets. It is also likely to provide superior performance for flows involving rotation, boundary layers under strong adverse pressure gradients, separation, and recirculation.

FLUENT is based on an unstructured grid solver using a finite volume approach for the solution of the Reynolds Averaged Navier-Stokes (RANS) equations. An unstructured computational grid was developed using the Gambit grid generator with approximately 1.8 million computational cells for each case. All the cases presented here converged to residual levels of the order of 10-8 for velocity components and energy equation and 10-5 for mass flow rate. An investigation of grid independence was carried out to find the proper mesh. The test was performed on the baseline.

The effectiveness measurements are made with the mainstream at ambient temperature, the coolant air heated, and the test surface unheated. Because the test surface is unheated and well insulated, it is assumed to be adiabatic. Therefore the local wall temperature at steady state conditions measured by the thermocouples is now the adiabatic wall temperature, $T_{a w}$. Since the test surface is adiabatic, there is no heat transfer at the surface. As a result, the local film temperature, $T_{f}$, is equal to the corresponding adiabatic wall temperature, $T_{a w}$. Now the following equation can be used to calculate the film cooling effectiveness.

$$
\eta=\frac{T_{a w}-T_{m}}{T_{c}-T_{m}}
$$

This method of calculating the film effectiveness has been used by several researches such as Ou et al. [15] and Mehendale and Han [14]. A more precise method of estimating uncertainty in experimental results has been presented by Kline and McClintock [12]. The calculated uncertainty of the film cooling effectiveness is found to be about $\pm 1.55 \%$.

\section{Results and Discussions}

Figures (6), (7), and (8) show a comparison between the boundary layer velocity distributions colored by effectiveness under ZPG, APG, and FPG for baseline case, case-1, and case-3at different values of velocity ratios. The boundary layer velocity distributions of case- 2 are not represented because it is close to case- 1 in profile. The results of VR $=1.5$ are not presented also because they are close to that of $\mathrm{VR}=1$. The boundary layer velocity distribution will be presented in $\mathrm{y}-\mathrm{z}$ plan from $\mathrm{z} / \mathrm{D}=-1.5$ to $\mathrm{z} / \mathrm{D}=1.5$ at $\mathrm{x} / \mathrm{D}=4$ due to clear details of the interaction between the mainstream flow and the coolant jets.

For Baseline case, Figure (6) shows two vortices due to the interaction between the mainstream flow and the jet flow. As the velocity ratio increases, the two vortices lift off the coolant jet away from the test surface due to high momentum flux. As the APG is applied, there is a suction area appearing near the top surface of the test section causing the free stream 
flow to move upward but due to the mass flux with respect to the cross-section area, the coolant jet still moves near the test surface. As the adverse pressure gradient increases, (APG(2)), the upward moving flow increases causing the coolant jet to lift off. Under FPG, the main flow has a velocity component moves towards the test surface and mitigate the coolant jet to move near the test surface.

For Case 1, figure (7) shows that there are new vortices, from the anti-vortex holes, appears above the two vortices coming out from the main hole. The new vortices try to move against the main hole vortices keeping the coolant flow near the test surface. This action is very clear with high velocity ratios but it is not clear with low velocity ratios because the fluid flow through the anti-vortex holes is taken from the main hole fluid and for low velocity ratios, the main hole flow is already low. When the adverse pressure is applied, the anti-vortex fluid flow is moving upward. Especially, the anti-vortex holes is upstream the main hole, that causes the coolant jet to move away from the test surface which reduces the film cooling effectiveness at the test surface. But under the favorable pressure gradient the film cooling effectiveness increases due to the downward velocity component which keeps the coolant jets from the main hole and the anti-vortex holes near the test surface. Case 2 has the same performance like case 1 because the anti-vortex holes are still upstream the main hole. But it is clearly that the flow from the anti-vortex holes is moving beside the flow from the main hole and creates new vortices against the main hole vortices but with covering a wider area than that covers in case 1.

For case 3, the fluid flow from the anti-vortex holes is moving below the fluid flow from the main hole because the anti-vortex holes are in line with the main hole and have a less momentum flux than the main hole. So, as shown in figure (8) the two vortices coming out from the main hole are lift off by the flow from the anti-vortex holes. When the pressure is applied the flow from the anti-vortex holes is still moving beside the test surface and saving by the main flow hole. So, there is no a significantly affect due to applied pressure gradient.

The detailed film cooling will be presented in this section from the numerical results. The experimental results film cooling effectiveness is available at the measured stations only at which thermocouples are used to measure the test surface temperature.

Figure (9) shows the effect of velocity ratio on detailed film cooling effectiveness distributions for all studied cases under both ZPG and APG(1). The shown data in this figure is taken at the test surface downstream the film holes (at $\mathrm{y}=0$ ).

For baseline case, figure (9(a)) shows that the highest film cooling effectiveness occurring with the lowest velocity ratio (VR $=0.5$ ) for both $\mathrm{ZPG}$ and APG(1). As the velocity ratio increases, the momentum ratio increases causing the jet to penetrate the mainstream flow and lift-off away from the test surface. So the film cooling effectiveness decreases as the velocity ratio increases.

For case 1, the anti vortex holes are half the size of the main hole and exit upstream of the main hole. Figure (9(b)) shows that the film cooling effectiveness is higher than baseline case for all velocity ratios but the trend is different, as the velocity ratio increases the film cooling effectiveness increases and covers bigger area. The anti-vortex pair cause reduced flow through the main hole and also supplements the overall coverage in the region between the holes. The highest effectiveness occurs at $\mathrm{VR}=2.0$. The effect of this anti-vortex pair appears to mainly reduce the coolant momentum flux from the main holes. The effect of APG(1) 
appears slightly different from ZPG but the covered area, downstream the coolant jet, appears thinner and shorter under APG(1) than ZPG especially with higher velocity ratio.

For case 2, as shown in figure (9(c)), the anti vortex holes are also half the size of the main hole and still exit upstream of the main hole but more close to the main hole than in case 1 . Like in case 1, the film effectiveness increases as the velocity ratio increases.

In case 3, as shown in figure (9(d)) the anti vortex holes are also half the size of the main hole but exit in the same line with the main hole. The trend of the film effectiveness is return to be similar to that of the baseline just downstream the main hole, as the velocity ratio increases, the film effectiveness decreases. But the film effectiveness is still higher than that of the baseline case. The figure shows that the film cooling effectiveness covered area gets narrower as the flow moves downstream the film holes. The flow from anti-vortex holes moves under the flow from the main holes causing the main hole jet to lift off from the surface especially with higher velocity ratios. The effect of APG(1) is slightly different from ZPG.

Figure (10) shows the detailed film cooling effectiveness under APG(2) and FPG for studied cases with different velocity ratios. For all studied velocity ratios, the anti-vortex cases show a higher film cooling effectiveness as compared with baseline case for both adverse and favorable pressure gradients. But for the same case as the velocity ratio increases, the film cooling effectiveness increases except with the baseline case. For all studied cases, the film cooling effectiveness under FPG covers a wider area as compared with other adverse pressure gradients.

The spanwise averaged is calculated for points from $\mathrm{z} / \mathrm{D}=1.5$ to $\mathrm{z} / \mathrm{D}=-1.5$, it means that the spanwise averaged film cooling effectiveness will be presented downstream the middle hole.

It can be seen that computational predictions for the studied cases are much higher than for the experimental data. It has always been indicated by previous film cooling prediction studies that the CFD results cannot predict the spreading of jets accurately and over predict centerline effectiveness. The spanwise averaged results show similarities as the cross-stream direction is averaged and washes out the local discrepancies between the predictions and experiments [18]. The maximum deviation between the numerical and experimental results as a ratio of numerical results for the overall area averaged film cooling effectiveness is about $2.3 \%$ at $\mathrm{VR}=2.0$ and $21.7 \%$ at $\mathrm{VR}=0.5$ for baseline case. But for case 1 , the maximum deviation is about $34.9 \%$ at $\mathrm{VR}=2.0$ and $21.6 \%$ at $\mathrm{VR}=0.5$.

For VR $=0.5$, Figure (11) shows that, for all cases the average spanwise film effectiveness decreases as $\mathrm{x} / \mathrm{D}$ increases. The momentum ratio at $\mathrm{VR}=0.5$ is low and accordingly the jet flow doesn't penetrate the main stream flow. It moves below the main stream flow and the film cooling effectiveness continuous to decrease with $\mathrm{x} / \mathrm{D}$ for all cases. The anti-vortex cases give a higher film cooling effectiveness as compared with baseline case. The film cooling effectiveness with anti-vortex cases appears close to each other. Such improvement in film cooling effectiveness can be explained by the close contact between the cooling fluid and the surface For VR $=1.0$, Figure (12) shows that, baseline case has a different trend as compared to other cases. For baseline case, the film effectiveness starts from high value near the hole exit and begins to decrease rapidly until $\mathrm{x} / \mathrm{D}=7$ then the film effectiveness begins to increase slowly. Case 1 and case 2 have the same trend (as the coolant fluid is moving downstream the film holes, the film effectiveness decreases gradually). For case 3, as the coolant fluid is moving downstream the film holes, the film effectiveness decreases rabidly. 
For VR $=1.5$, Figure (13) shows that, the baseline film effectiveness has the same trend as the baseline film effectiveness for VR $=1.0$ but with lower values. The numerical results show that, case 1 and 2 give the same spanwise film effectiveness with small decreasing as moving away from the film holes. But experimental results, case 1 and case 2 appear to have constant values of film cooling effectiveness along the test surface but with different values of each case. For case 3, the film effectiveness appears to start from a high value and decreases rapidly as the coolant jet fluid is moving downstream the film holes.

For VR $=2.0$, Figure (14) shows that all cases still give the same trend as compared to that given by VR $=1.5$. The highest spanwise averaged film cooling effectiveness is given by case 1. For both case 1 and case 2, the film effectiveness may be assumed to be constant along the studied area. Case 3 shows rabid decrease in film effectiveness as moving away from the film holes.

Figure (15) shows the overall area averaged film cooling effectiveness for all studied cases at different values of velocity ratios. The overall area averaged film cooling effectiveness is calculated for the area downstream the middle hole only. The overall area at which the averaged film cooling is calculated is ranged from $\mathrm{x} / \mathrm{D}=0$ to $\mathrm{x} / \mathrm{D}=25$, and $\mathrm{z} / \mathrm{D}=-1.5$ to $\mathrm{z} / \mathrm{D}$ $=1.5$ for $\mathrm{y} / \mathrm{D}=0$. The figure shows that:

For baseline case, as the velocity ratio increases, the overall film effectiveness decreases. For case 1 , as the velocity ratio increases, the overall film effectiveness increases. Case 1 gives the highest overall effectiveness at $\mathrm{VR}=2.0$. But for lower velocity ratios, all anti-vortex cases film effectiveness is closed to each.

Case 3 gives the lowest overall film effectiveness with higher velocity ratios if it is compared with case 1 and case 2 . The overall area averaged film cooling effectiveness for case 3 may be assumed constant as the velocity ratio increases.

From the above results, for baseline case, the momentum ratio increases with high velocity ratios, so the coolant jet has the ability to penetrate the mainstream flow. According to that, at high velocity ratios, the film cooling effectiveness starts from high value at the film cooling hole and suddenly decreases as moving away from the film cooling hole then starts to increase gradually as the jet flow mixes with the mainstream flow. For anti-vortex cases, the jet flow distributes through the main hole and the anti-vortex holes. In cases 1 and 2, the flow from the anti-vortex holes is moving above the flow from the main hole and is trying to mitigate it to move beside the test surface. But in case 3, the flow from the anti-vortex holes is moving inline with the flow from the main hole. So, in case 3, the film cooling effectiveness start from the highest value but it decreases rabidly as compared with case 1 and 2.

Figures (16) and (17) show a comparison between the present work and previous works under $\mathrm{ZPG}$ at VR $=2.0$ for baseline case and case 1, respectively. Dhungel [3] baseline result was taken for $1 / 2$ inch main hole diameter with angle of inclination equal $30^{\circ}$. Dhungel used infrared camera to measure the temperature distribution on the test surface. Jung et. al. [11] studied the effect of orientation angle. Their baseline was a hole with $35^{\circ}$ inclination angle and $20 \mathrm{~mm}$ diameter. They used liquid crystal technique to measure the temperature distribution.

While the results of Heidmann [8] were a numerical results carried out by using the 3-D Navier-Stokes solver Glenn-HT. 
Figures (18), (19), and (20) show the numerical spanwise averaged film cooling effectiveness distribution for baseline under different pressure gradients at VR $=0.5,1.0$, and 2.0, respectively. At VR $=0.5$, figure (18) shows that, both adverse and favorable pressure gradients reduce the film cooling effectiveness but with a slight difference as compared with ZPG. At VR $=1.0$, figure (19) shows that, both adverse and favorable pressure gradients increase the film cooling effectiveness as compared with ZPG. At VR $=2.0$, the film cooling effectiveness under adverse pressure gradient is very close to that under ZPG, while under favorable pressure gradient, it increases with a significant effect.

Figures (21), (22), and (23) show the numerical spanwise averaged film cooling effectiveness distribution for case 1 under different pressure gradients at VR $=0.5,1.0$, and 2.0, respectively. The figures show that for all studied velocity ratios, the favorable pressure gradient increases the film cooling effectiveness while the adverse pressure gradient reduces the film cooling effectiveness. Further increase of the value of adverse pressure gradient shows higher reduction of film cooling effectiveness.

Figures (24), (25), and (26) show the numerical spanwise averaged film cooling effectiveness distribution for case 2 under different pressure gradients at VR $=0.5,1.0$, and 2.0, respectively. The figures show the same conclusion as that given by case 1 .

For Case 3, Figures (27), (28), and (29) show the numerical spanwise averaged film cooling effectiveness distribution under different pressure gradients at VR $=0.5,1.0$, and 2.0, respectively. The favorable pressure gradient increases the film cooling effectiveness with a slight difference at VR $=0.5$ and 1.0. While at VR $=2.0$, FPG reduces the film cooling effectiveness. On the other hand, the adverse pressure gradient decreases the film cooling effectiveness at $\mathrm{VR}=0.5$ and $\mathrm{VR}=1.0$ and increases it at $\mathrm{VR}=2.0$ but all of these increase and reduction with a small difference which may be concluded that the pressure gradient has no considrable effect at high velocity ratio.

\section{Conclusions}

A wind tunnel is constructed to study experimentally the effect of using anti-vortex holes branching out from the main film cooling holes on the film cooling effectiveness. Different values of velocity ratios VR, (coolant jet velocity/main stream velocity) namely $0.5,1.0,1.5$, and 2.0, are studied experimentally with three different positions of anti-vortex holes with and without adverse pressure gradient.

A Computational model is also used to study the same effect numerically. Four values of pressure gradients (ZPG, APG(1), APG(2), and FPG) are also considered. The following points represent the main conclusions.

1. Results show that the use of anti-vortex holes enhance the film cooling downstream the film cooling holes. It appears that the presence of anti vortex holes mitigates the effect of the kidney vortices and also reduces the momentum of the main jet hence improving the film coverage in both downstream and lateral direction.

2. For baseline case, as the velocity ratio increases, the overall area-averaged film cooling effectiveness decreases. On the contrary, for all cases with anti-vortex as the velocity ratio increases, the overall area averaged film cooling effectiveness increases.

3. Based on detailed numerical results, for Case 1 and 2, the coolant jet covers more area as compared with case 3 , especially, with high velocity ratios.

4. Under zero pressure gradient, The overall area averaged film cooling effectiveness generally increases with the use of anti-vortex. The increase ranges from $606 \%$ for high VR to $40 \%$ for low VR. 
5. The first studied adverse pressure gradient reduces the overall area averaged film cooling effectiveness by about $12.3 \%$ for case 1 at $\mathrm{VR}=2.0$ and about $9.2 \%$ for case 1 at $\mathrm{VR}=0.5$ as compared with case 1 under ZPG.

6. The favorable pressure gradient gives more enhancements to the film cooling effectiveness as compared with zero or adverse pressure gradient.

7. The large effect of anti-vortex on the overall area averaged film cooling effectiveness is not considerably affected by the reduction due to adverse pressure gradients.

\section{References}

[1] Ammari,H.D., Hay, N., and Lampard, D., 1990 "The Effect of Density Ratio on the Heat Transfer Coefficient from a Film Cooled Flat Plate." ASME Journal of Turbomachinery, Vol. 112, pp444-450.

[2] Andreopoulous ,J. and Rodi, W., 1984 Experimental Investigation of Jets in Crossflow Journal of Fluid Mechanics, Vol 138, pp 93-127.

[3] Dhungel, A., 2007, "Film Cooling from a Row of Holes Supplemented with Anti Vortex Holes" A Thesis for the degree of Master of Science in Mechanical Engineering, Louisiana State University.

[4] Dhungel, S., Phillips, A., Ekkad, S. V., and Heidmann, J. D., 2007, "Experimental Investigation of a Novel Anti-Vortex Film Cooling Hole Design," ASME Paper No. GT2007-27419.

[5] Foster, N.W., Lampard, D., "The Flow and Film Cooling Effectiveness Following Injection Through a Row of Holes", ASME Journal of Eng. Power 102 (1980) pp. 584588.

[6] Goldstein, R. J., Eckert, E. R. G., Eriksen, V. L., and Ramsey, J. W., 1970, "Film Cooling Following Injection Through Inclined Circular Tubes," Israel Journal of Technology, Vol. 8, No. 1-2, pp. 145-154.

[7] Haven, B. A., Yamagata, D. K., Kurosaka, M., Yamawaki, S., and Maya, T., 1997, "Anti-Kidney Pair of Vortices in Shaped Holes and Their Influence on Film Cooling Effectiveness," ASME Paper No. 97-GT-45.

[8] Heidmann, J. D., 2008, “A Numerical Study of Anti-Vortex Film Cooling Designs at High Blowing Ratio" NASA/TM-2008-215209.

[9] Heidmann, J. D., Ekkad, S., 2008, “A Novel Antivortex Turbine Film-Cooling Hole Concept" Journal of Turbomachinery, ASME, JULY 2008, Vol. 130.

[10] Jubran B and Brown A., 1985, "Film cooling from two rows of holes inclined in the streamwise and spanwise directions". ASME J Eng Gas Turbines Power,107:84-91.

[11] Jung, I. S., and Lee J. S., 2000, "Effects of Orientation Angles on Film Cooling Over a Flat Plate: Boundary Layer Temperature Distributions and Adiabatic Film Cooling Effectiveness" Journal of Turbomachinery, ASME, Jan 2000, Vol.122, pp 153 - 160.

[12] Kline, S.J. and McClintock, F.A., 1953, "Describing Uncertainties in Single Sample Experiments," Mechanical Engineering, Vol. 75, pp. 3-8.

[13] Lemmon, C. A., Kohli, A., and Thole, K. A., 1999, "Formation of Counter-Rotating Vortices in Film-Cooling Flows," ASME Paper No. 99-GT-161.

[14] Mehendale, A.B., and Han, J.C., 1992, "Influence of High Mainstream Turbulence on Leading Edge Film Cooling Heat Transfer: Effect of Film Hole Spacing," Int. J. of Heat Mass Transfer, 35, No. 10, pp. 2593-2604.

[15] Ou, S., Han, J.C., Mehendale, A.B., and Lee, C.P., 1994, "Unsteady Wake Over a Linear Turbine Blade Cascade with Air and CO2 Film Injection. Part I: Effect on Heat Transfer Coefficients.” ASME J. Turbomachinery, 116, pp. 721-729.

[16] Ralph J. Volino, 2003, "Passive Flow Control on Low-Pressure Turbine Airfoils" ASME, J. Turbomachonery. Vol. 125(4), Dec 01, 2003, 754-764. 
[17] Teekarama A.J.H., Forth C.J.P., Jones T.V., 1991, "Film cooling in the presence of mainstream pressure gradients". ASME J Turbomach, 113:484-92.

[18] Yiping Lu, "Effect of Hole Configurations on Film Cooling from Cylindrical Inclined Holes for The Application to Gas Turbine Blades", partial fulfillment of the requirements for the degree of Doctor of Philosophy, Louisiana State University, December 2007.

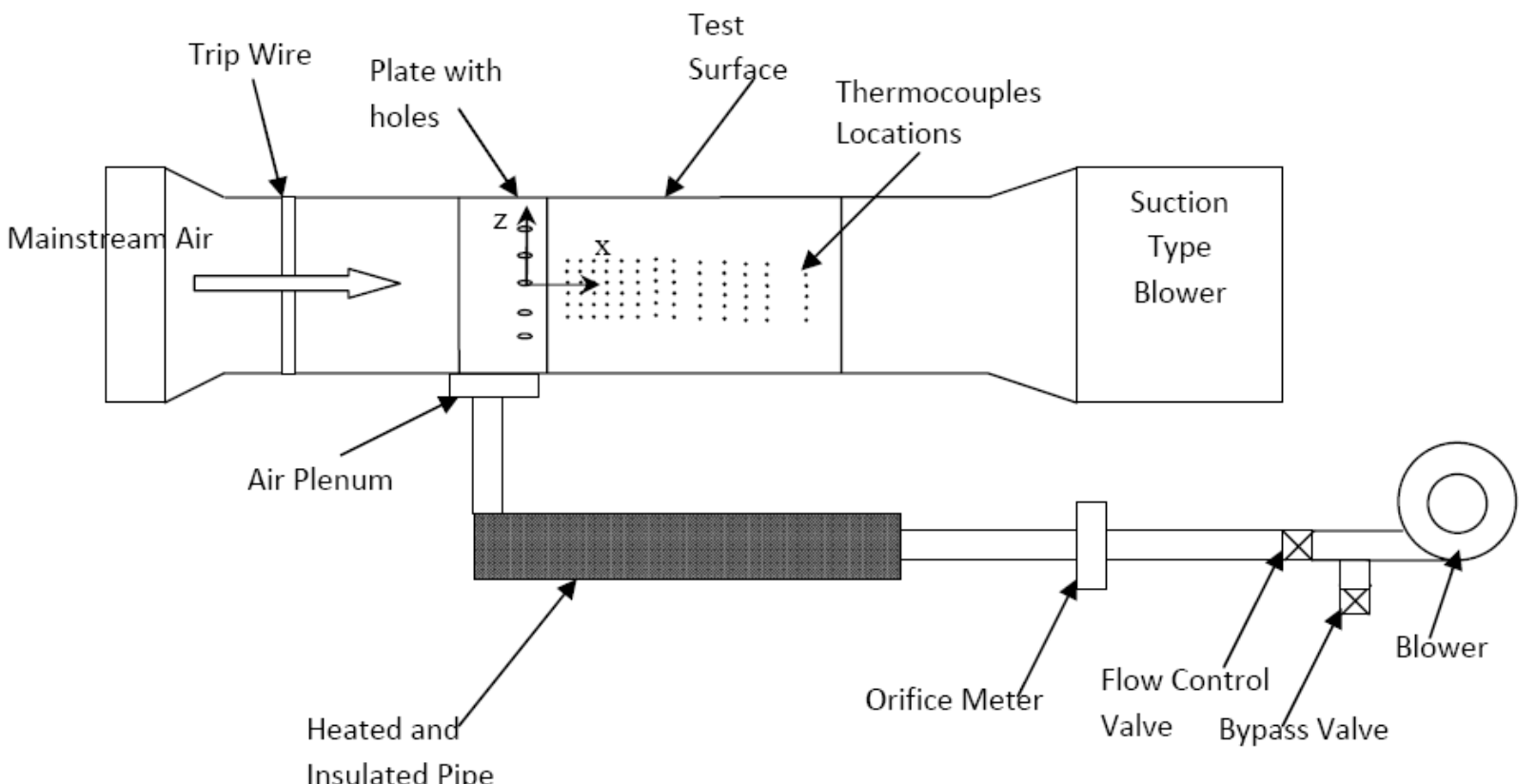

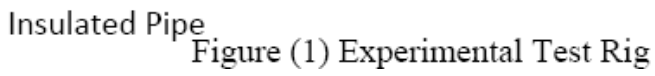

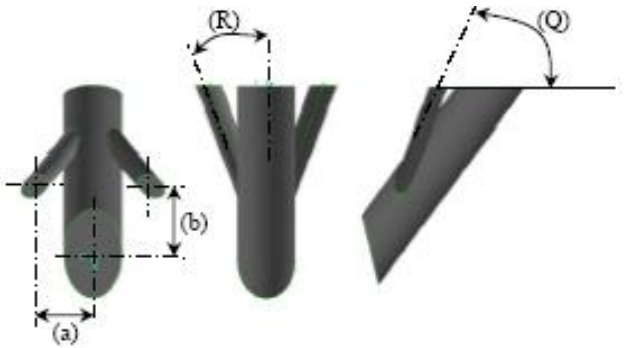

a) Anti Vortex Hole Configuration

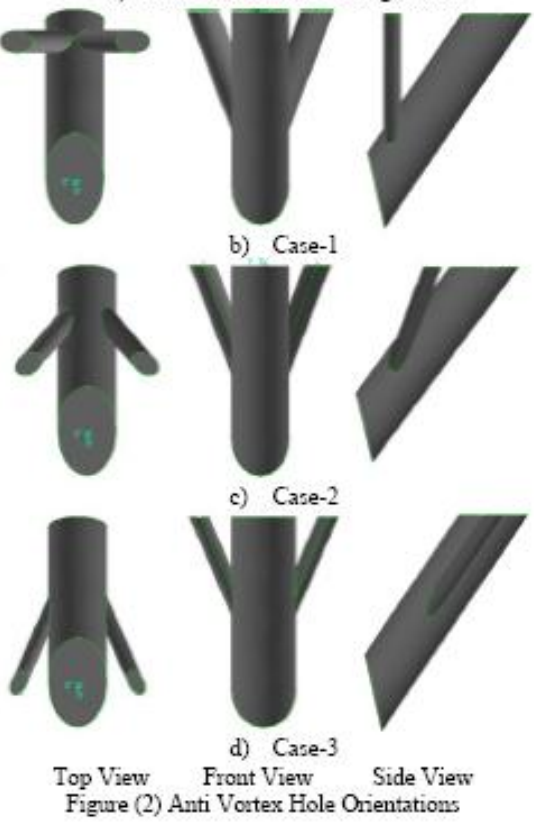



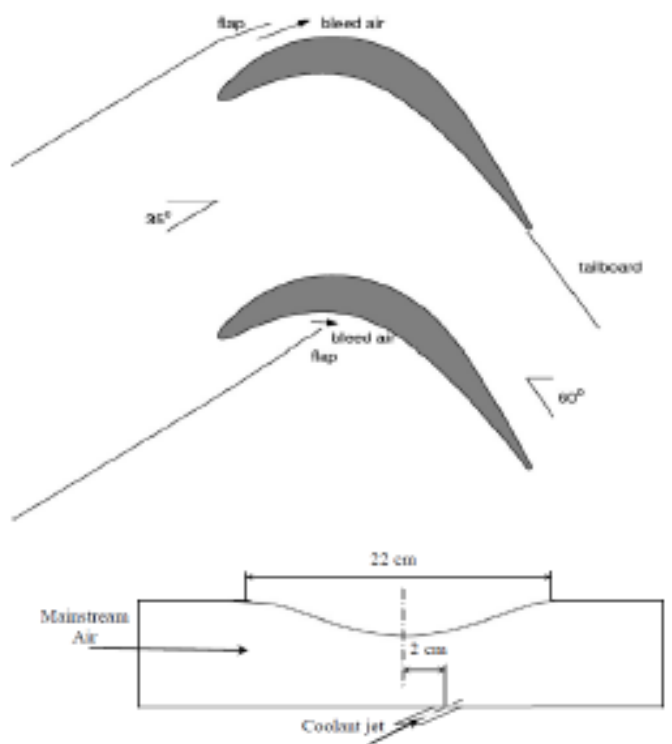

a) $\mathrm{APG}(1)$

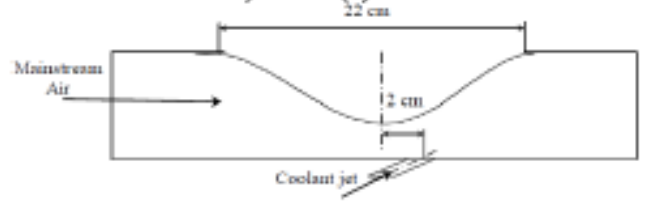

b) $\mathrm{APG}(2)$

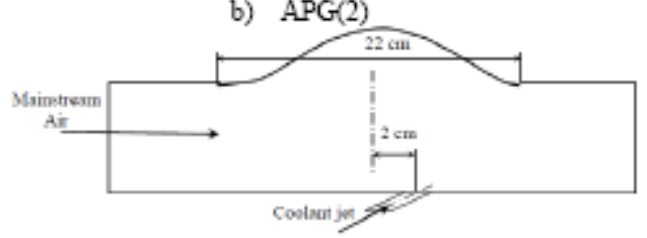

c) FPG

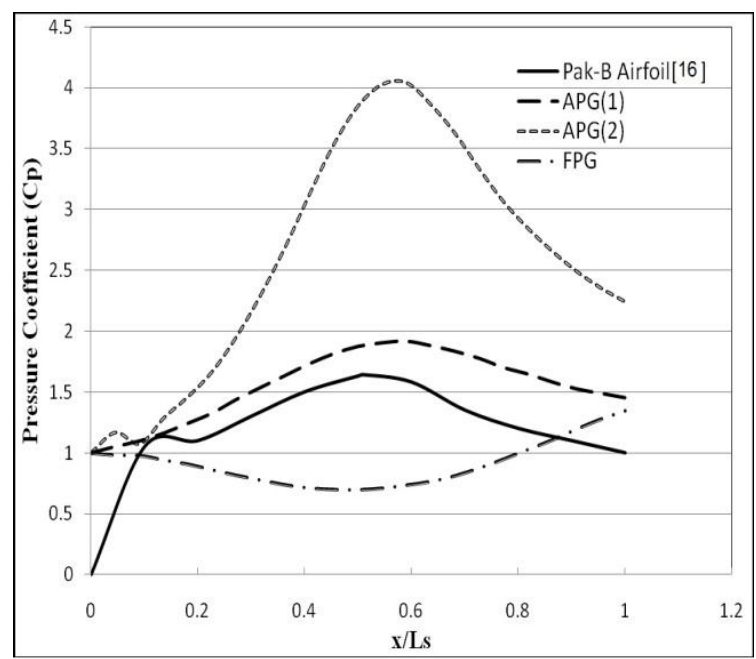

d) The pressure coefficient profiles

Figure (4) studied wedges schematic and the pressure coefficient profiles over the flat plate test section with wedges as compared with Pak-B Airfoil

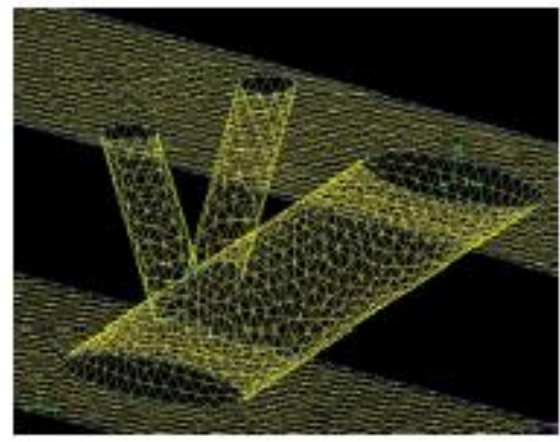

Figure (5) Hole Intersection Grid Close-Up 

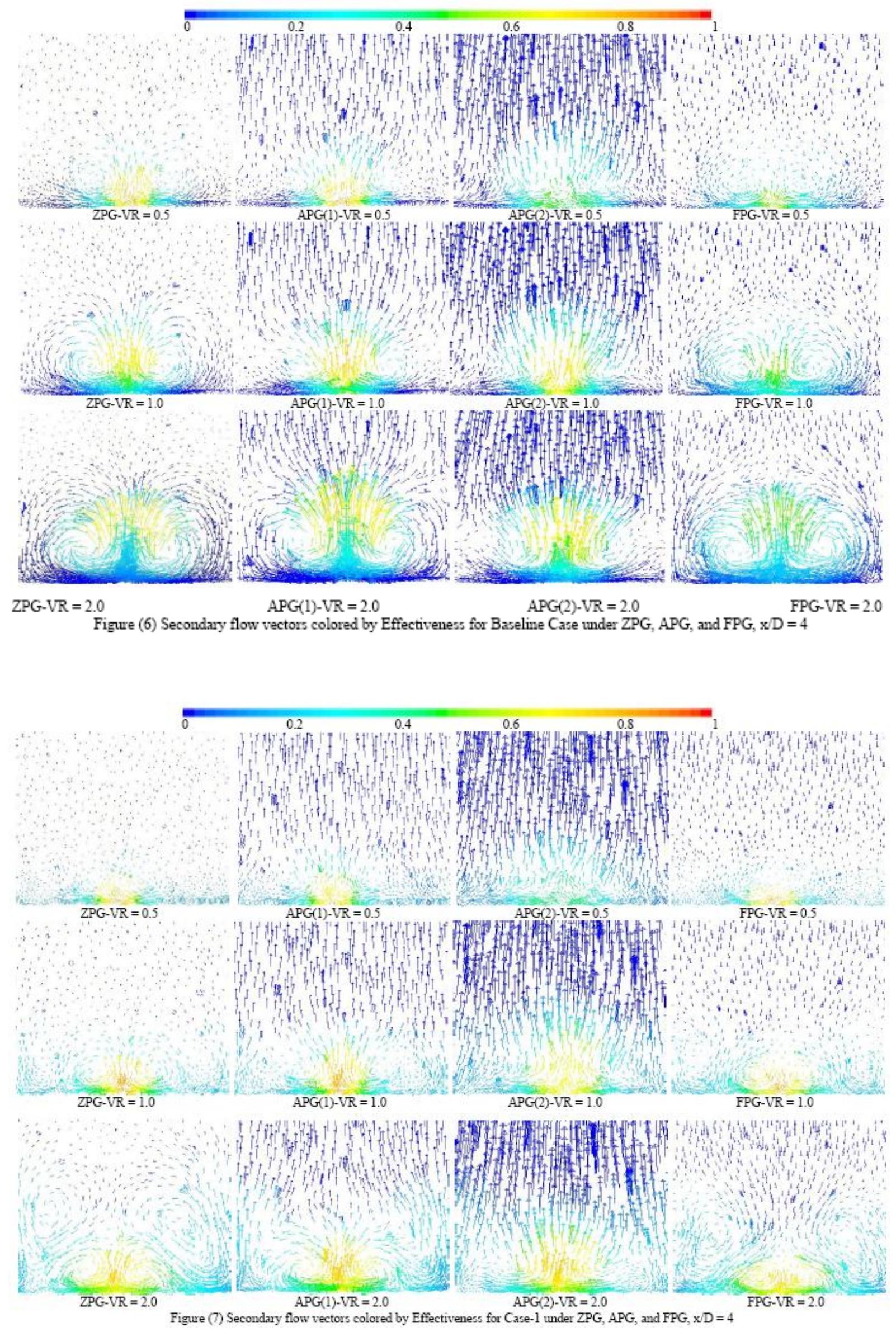


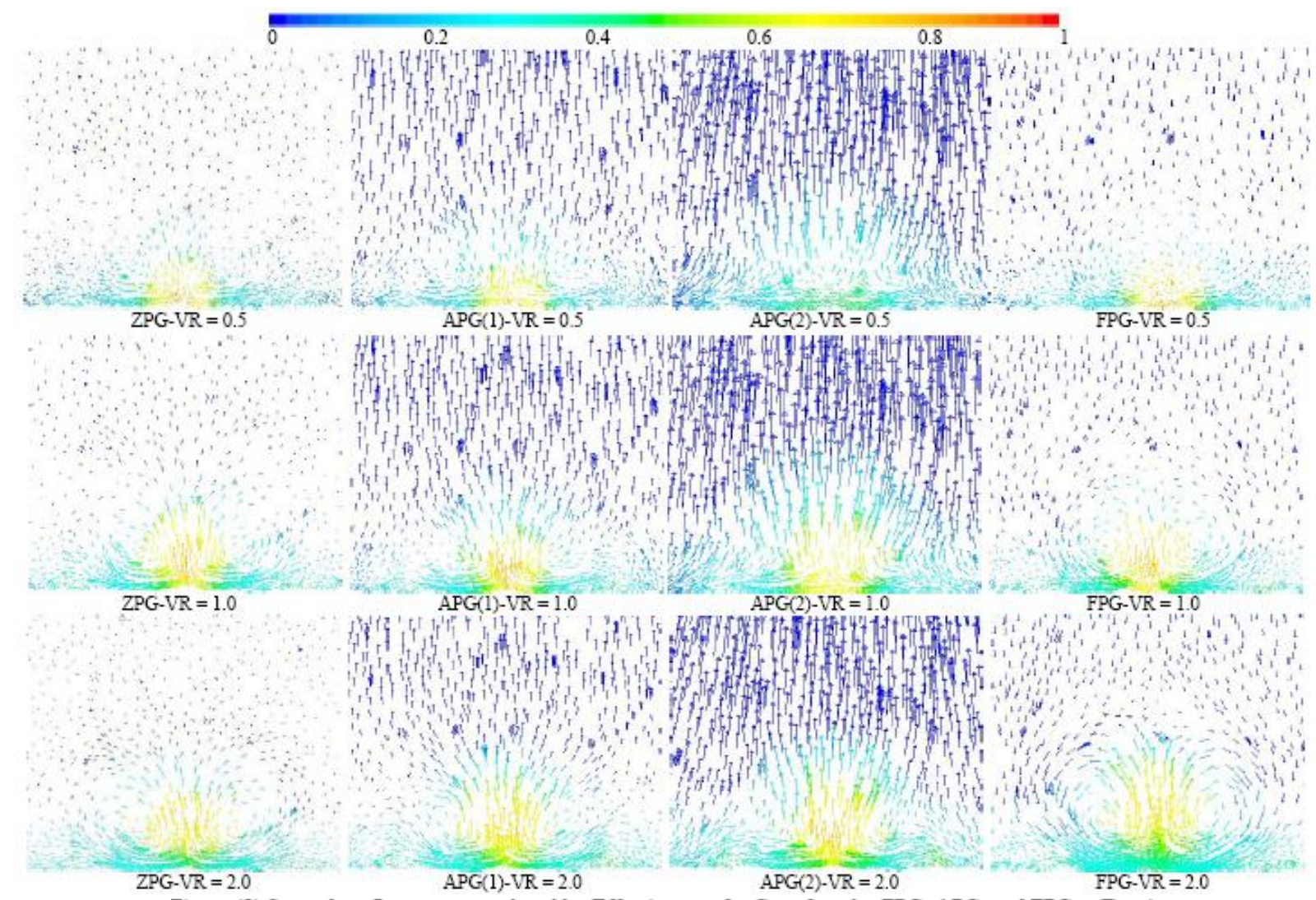

Figure (8) Secondary flow vectors colored by Effectiveness for Case-3 under ZPG, APG, and FPG, $x / D=4$

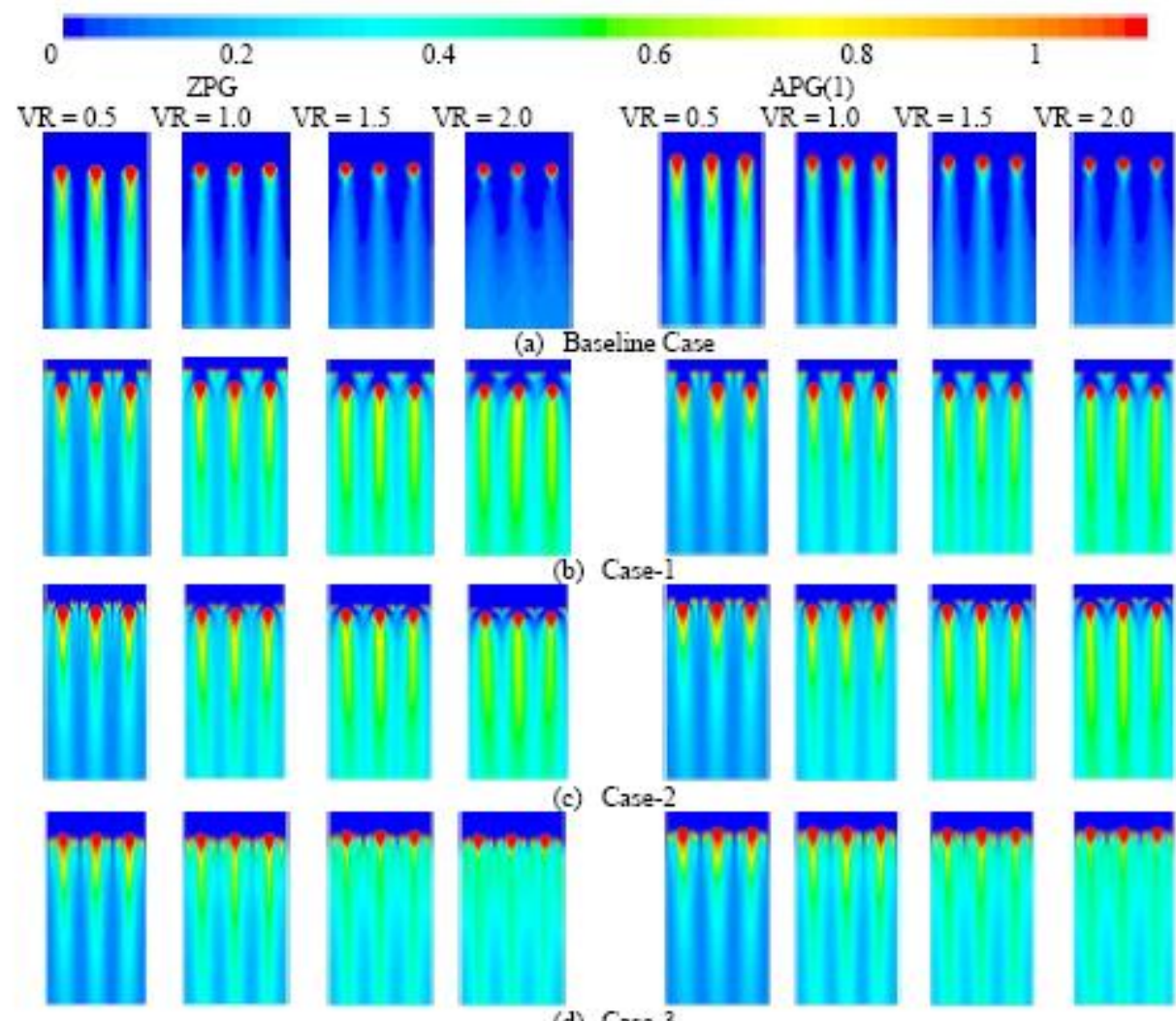

Figure (9) Detailed Film Cooling Effectiveness Distributions for Studied Cases at different Velocity ratios under ZPG and APG(1) 


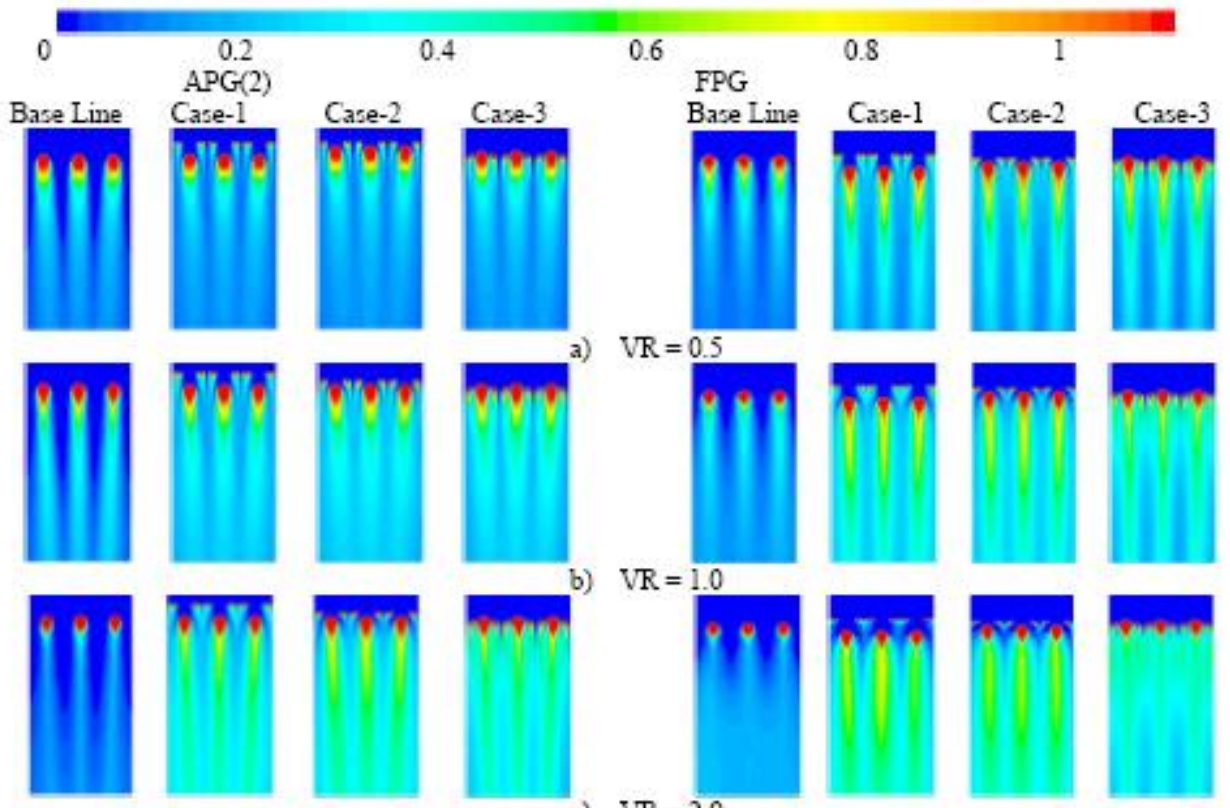

Figure (10) Detailed Film Cooling Effectiveness Distributions for Studied Cases at different Velocity ratios under APG(2) and FPG

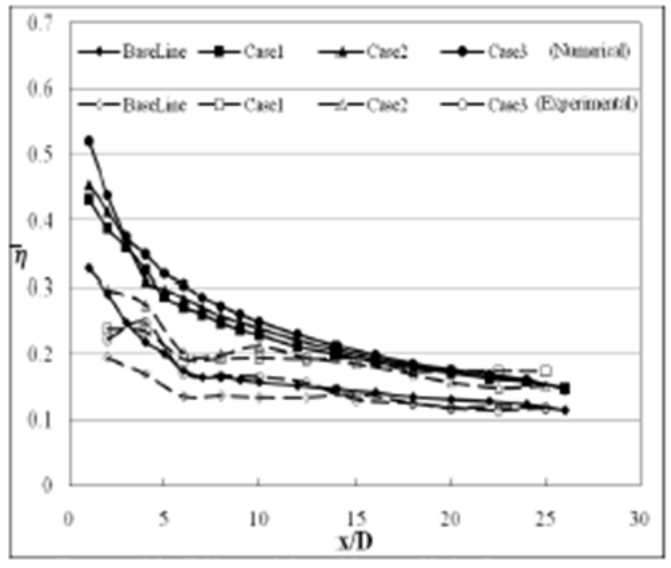

Figure (11) Effect of anti-vortex hole geometry on spanwise averaged film cooling effectiveness distributions at $\mathrm{VR}=0.5$ under $\mathrm{ZPG}$

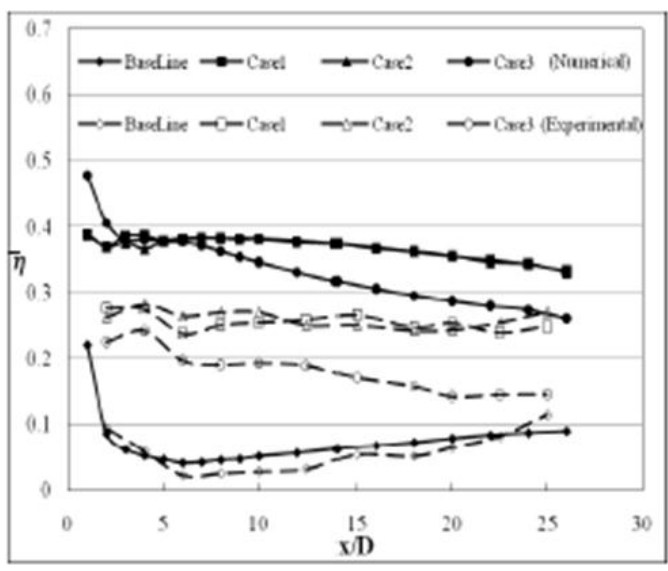

Figure (13) Effect of anti-vortex hole geometry on spanwise averaged film cooling effectiveness distributions at $\mathrm{VR}=1.5$ under $\mathrm{ZPG}$

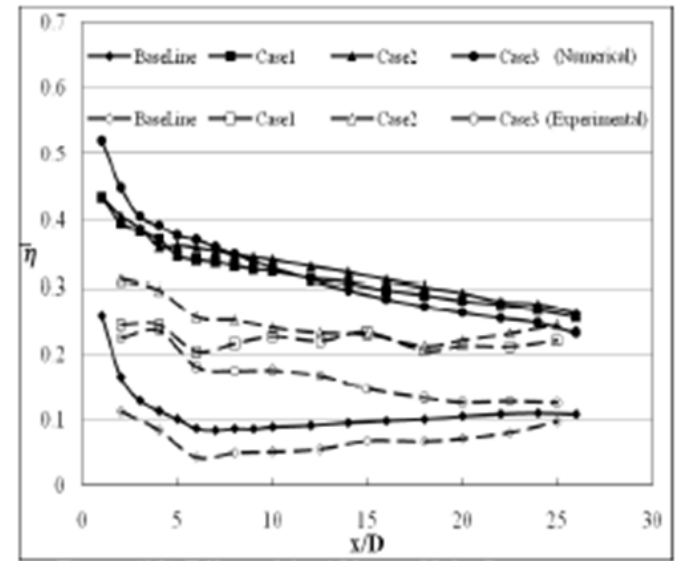

Figure (12) Effect of anti-vortex hole geometry on spanwise averaged film cooling effectiveness distributions at $\mathrm{VR}=1.0$ under $\mathrm{ZPG}$

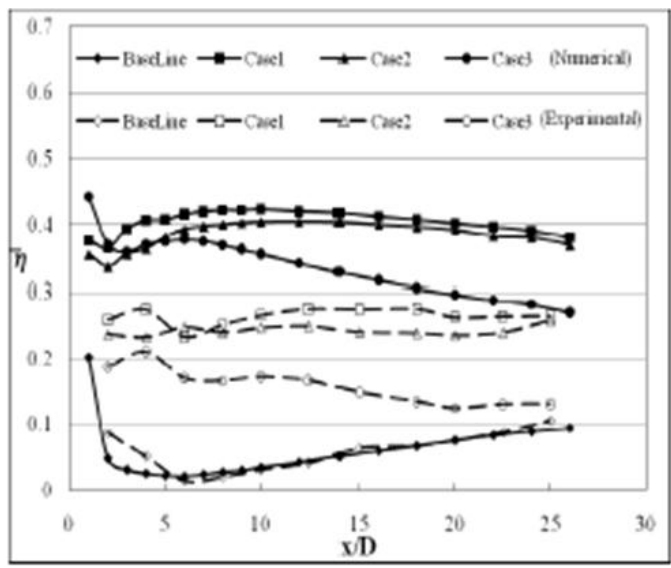

Figure (14) Effect of anti-vortex hole geometry on spanwise averaged film cooling effectiveness distributions at $\mathrm{VR}=2.0$ under $\mathrm{ZPG}$ 


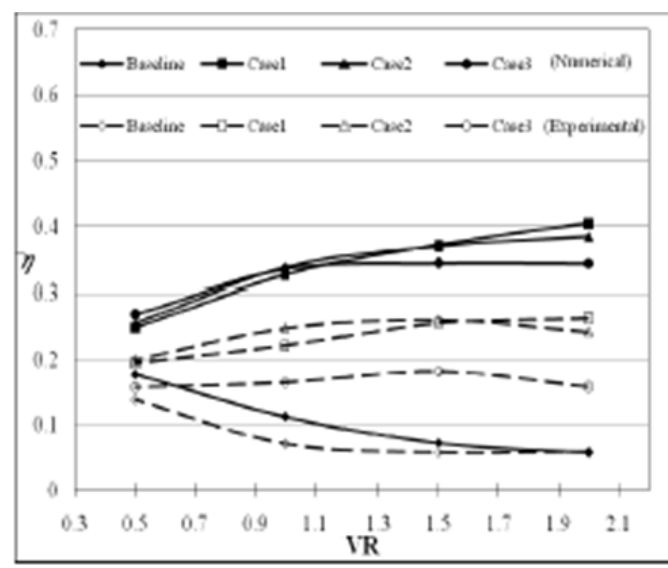

Figure (15) The overall averaged area film cooling effectiveness for all studied cases with different velocity ratios

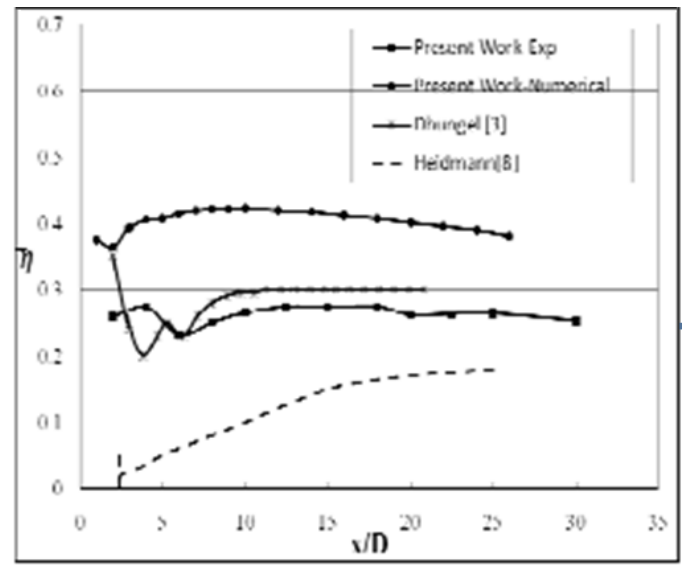

Figure (17) Comparison of spanwise averaged film cooling effectiveness distribution for case $\mathbf{1 ,} \mathrm{VR}=\mathbf{2 . 0}$

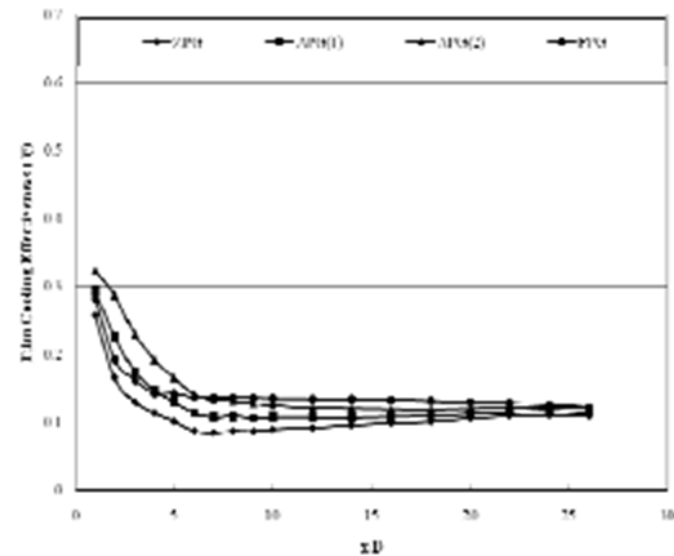

Figure (19) Spanwise averaged film cooling effectiveness for base line case under different pressure gradients at $\mathrm{VR}=\mathbf{1 . 0}$

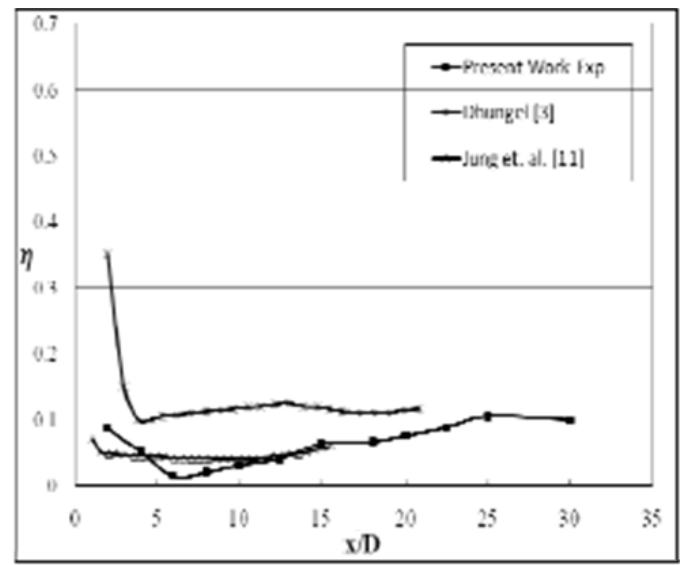

Figure (16) Comparison of spanwise averaged film cooling effectiveness distribution for base line case, $\mathbf{V R}=\mathbf{2 . 0}$ under $\mathrm{ZPG}$

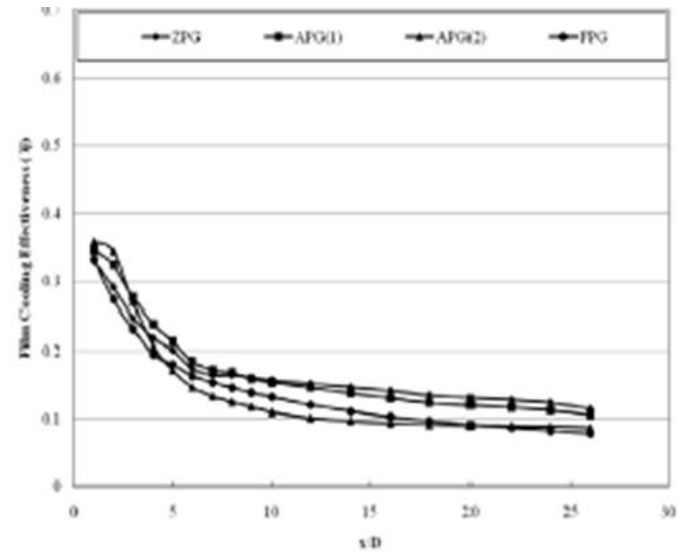

Figure (18) Spanwise averaged film cooling effectiveness for base line case under different pressure gradients at $\mathrm{VR}=\mathbf{0 . 5}$

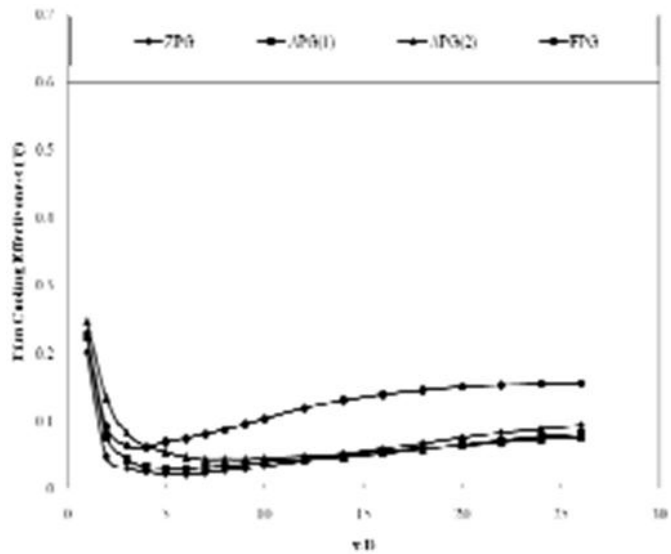

Figure (20) Spanwise averaged film cooling effectiveness for base line case under different pressure gradients at $\mathrm{VR}=\mathbf{2 . 0}$ 


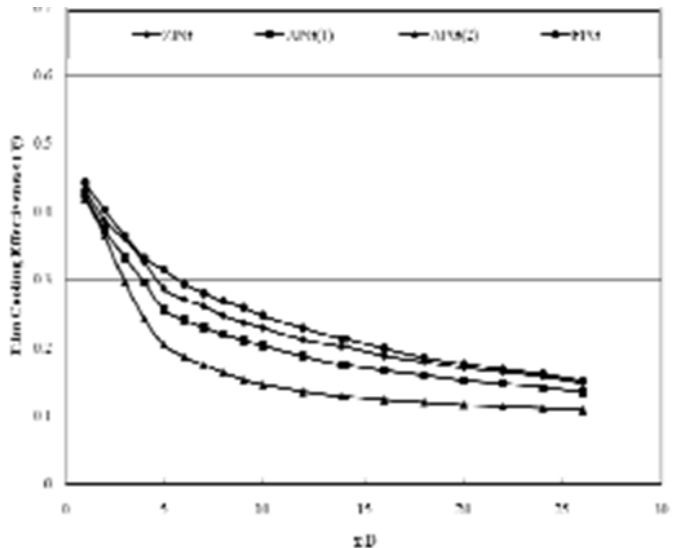

Figure (21) Spanwise averaged film cooling effectiveness for case 1 under different pressure gradients at $\mathrm{VR}=0.5$

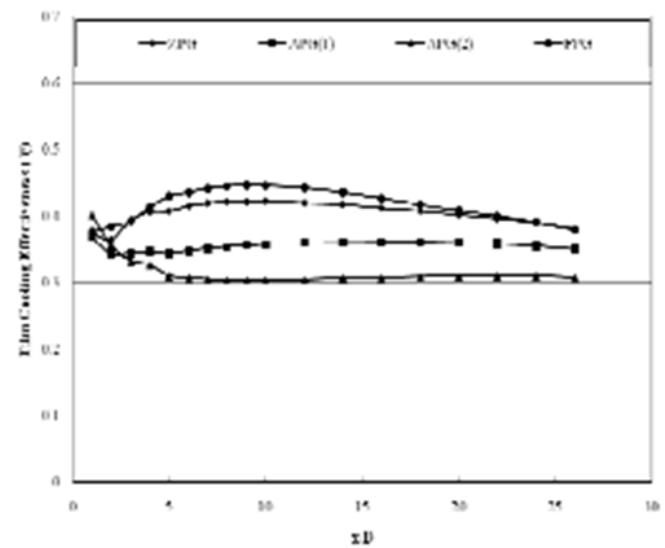

Figure (23) Spanwise averaged film cooling effectiveness for case 1 under different pressure gradients at $\mathrm{VR}=\mathbf{2 . 0}$

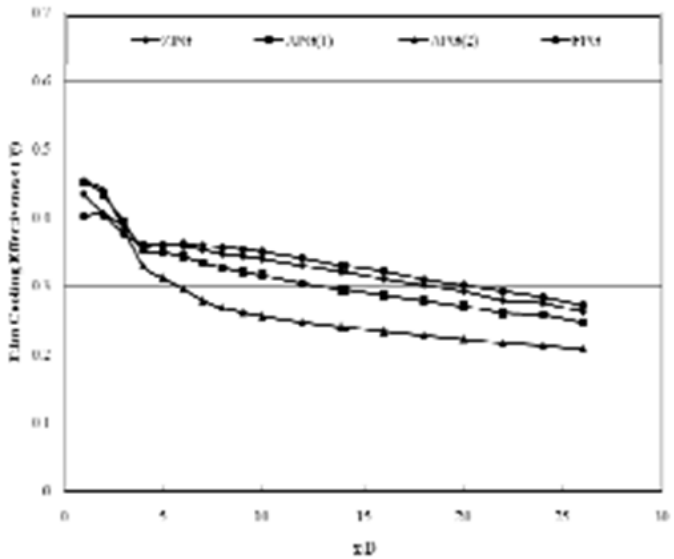

Figure (25) Spanwise averaged film cooling effectiveness for case 2 under different pressure gradients at $\mathrm{VR}=1.0$

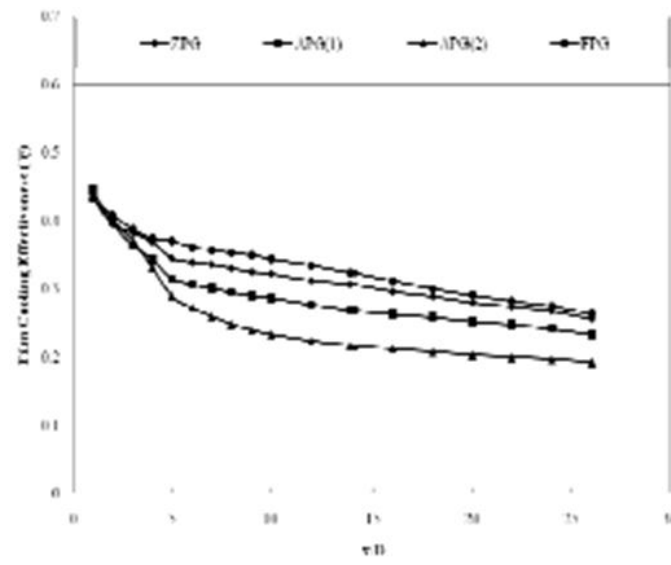

Figure (22) Spanwise averaged film cooling effectiveness for case 1 under different pressure gradients at $V R=1.0$

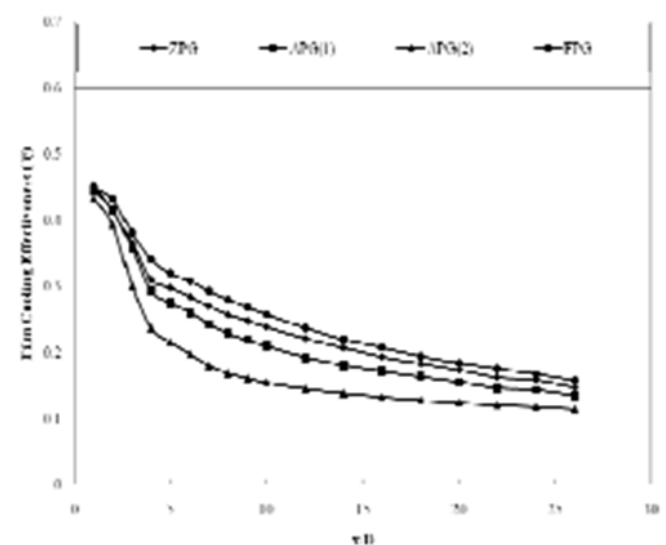

Figure (24) Spanwise averaged film cooling effectiveness for case 2 under different pressure gradients at $\mathrm{VR}=0.5$

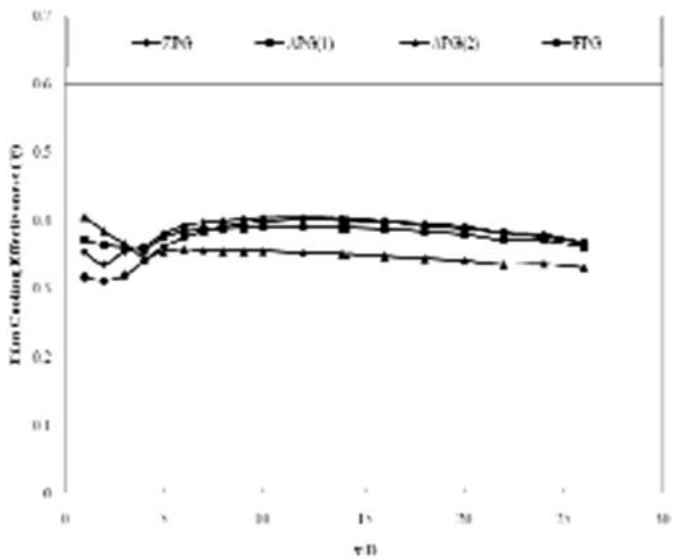

Figure (26) Spanwise averaged film cooling effectiveness for case 2 under different pressure gradients at $\mathrm{VR}=\mathbf{2 . 0}$ 


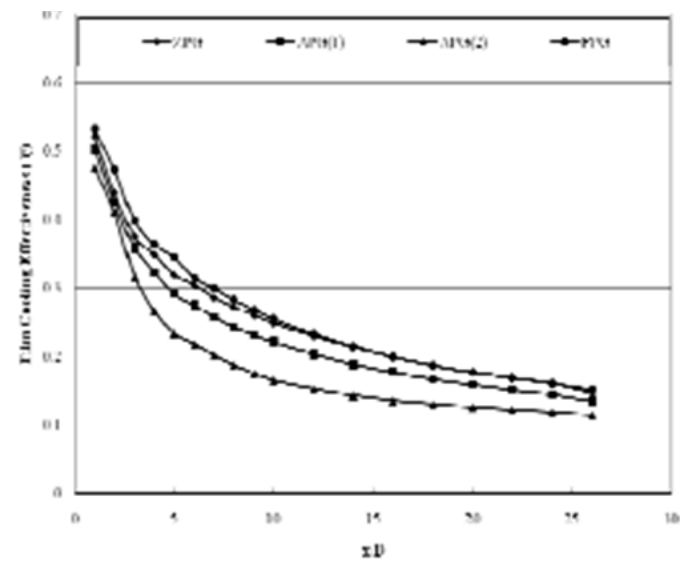

Figure (27) Spanwise averaged film cooling effectiveness for case 3 under different pressure gradients at $\mathrm{VR}=0.5$

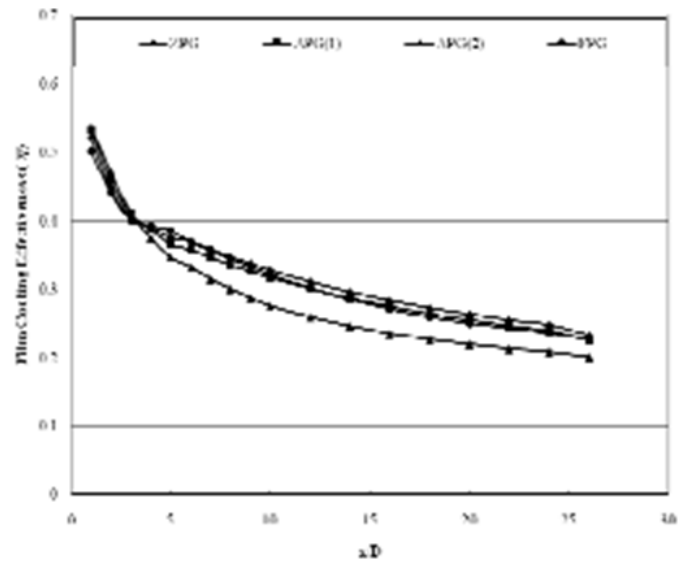

Figure (28) Spanwise averaged film cooling effectiveness for case 3 under different pressure gradients at $\mathrm{VR}=1.0$

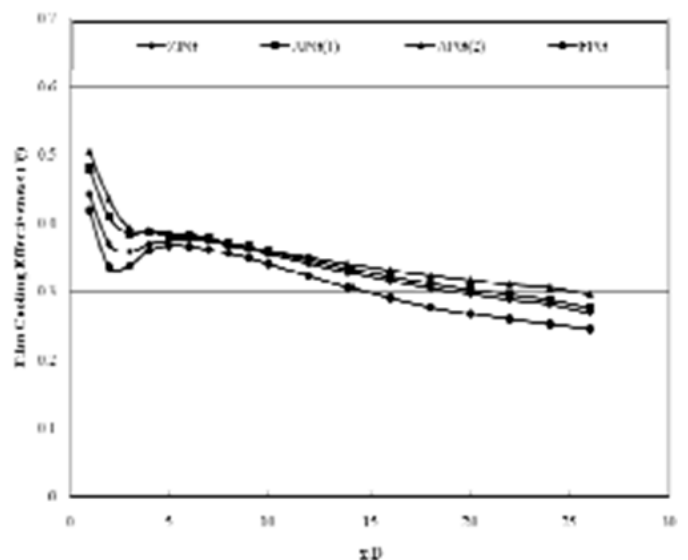

Figure (29) Spanwise averaged film cooling effectiveness for case 3 under different pressure gradients at $\mathrm{VR}=\mathbf{2 . 0}$ 